\title{
The periodic table of photosynthetic purple non-sulfur bacteria: intact cell-metal ions interactions
}

\author{
Matteo Grattieri ${ }^{1,2}$ (D) $\cdot$ Rossella Labarile $^{1,2}\left(\mathrm{D} \cdot\right.$ Gabriella Buscemi $^{1,2}$ (D) $\cdot$ Massimo Trotta $^{2}$ (D)
}

Received: 19 July 2021 / Accepted: 12 October 2021 / Published online: 8 November 2021

(c) The Author(s) 2021

\begin{abstract}
Photosynthetic purple non-sulfur bacteria (PNB) have been widely utilized as model organisms to study bacterial photosynthesis. More recently, the remarkable resistance of these microorganisms to several metals ions called particular interest. As a result, several research efforts were directed toward clarifying the interactions of metal ions with PNB. The mechanisms of metal ions active uptake and bioabsorption have been studied in detail, unveiling that PNB enable harvesting and removing various toxic ions, thus fostering applications in environmental remediation. Herein, we present the most important achievements in the understanding of intact cell-metal ions interactions and the approaches utilized to study such processes. Following, the application of PNB-metal ions interactions toward metal removal from contaminated environments is presented. Finally, the possible coupling of PNB with abiotic electrodes to obtain biohybrid electrochemical systems is proposed as a sustainable pathway to tune and enhance metal removal and monitoring.
\end{abstract}

\section{Graphic abstract}

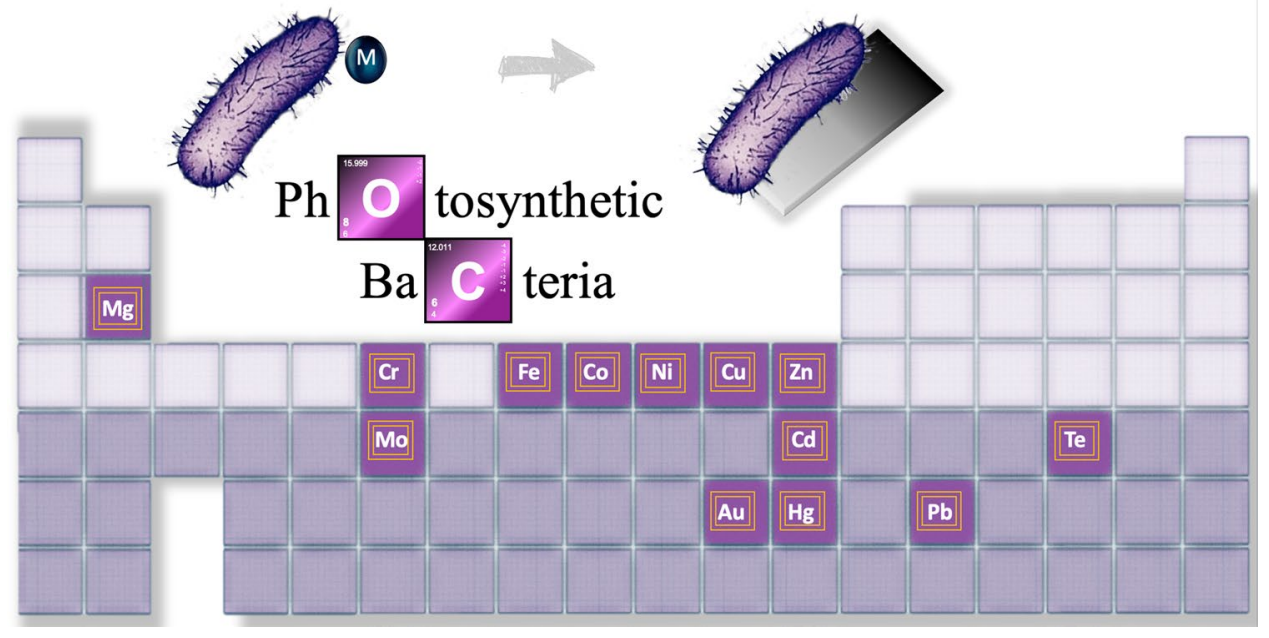

Keywords Heavy metals $\cdot$ Purple bacteria $\cdot$ Metal ions removal $\cdot$ Environmental monitoring $\cdot$ Biohybrid systems . Photobioelectrochemistry $\cdot$ Bioremediation

Matteo Grattieri

matteo.grattieri@uniba.it

$\triangle$ Massimo Trotta

massimo.trotta@cnr.it

Extended author information available on the last page of the article 


\section{Introduction}

Purple non-sulfur bacteria (PNB) are fascinating anoxygenic photosynthetic microorganisms capable of performing a great variety of light-dependent and light-independent reactions. Their photosynthetic metabolism exploits the enzyme reaction center, where the photochemistry takes place transducing solar energy and driving the metabolism of the organism. PNB, the dominant photoheterotrophs class of bacteria, are very versatile being capable of various metabolism spanning from photoautotrophic and photoheterotrophic to chemotrophic [1-3].

This unique characteristic led to their application as model organisms for the study of the effects of environmental parameters, substrates, and contaminants on the metabolism of photosynthetic bacteria [4]. As discussed in detail below, particular focus has been posed on unveiling the influence and the interaction of various heavy metal ions with PNB, leading to building up their own "periodic table". Traces of metal-ions play essential roles in many proteins and their availability is critical for the functioning of the photosynthetic and respiratory electron transport chain in bacteria [5]. However, high concentrations of metal ions can be harmful to microorganisms, and dedicated regulatory systems have been evolved to avoid/limit their toxic effects. Here we will first introduce and discuss the studies that provided a critical understanding of PNB-metal ions interactions. Toxicity, effects on cell metabolism, mechanisms of metal uptake, and the various approaches utilized to study these aspects are reviewed. Following, the possibility to implement PNB in a contaminated environment with toxic metal ions is investigated. Various approaches for metal removal, monitoring, and metal-nanoparticles synthesis are presented. Finally, the enthralling possibility of establishing an electrochemical communication between intact PNB cells and abiotic electrodes, thus "electrically wiring" a biotic and an abiotic component, is explored. While this latter aspect has been investigated only relatively recently, the detailed understanding of bacteria-metal interactions at the metabolic level poses the bases for the development of biohybrid electrochemical systems for enhanced environmental remediation and monitoring. In conclusion, the future possibilities and major challenges for technologies based on the periodic table of PNB are discussed.

\section{PNB-metal ions interaction}

In 1992, the resistance or tolerance of PNB to heavy metals was first noticed in a pioneering study performed by Moore and Kaplan focusing on tellurite $\left(\mathrm{TeO}_{3}{ }^{2-}\right)$ [6]
Commonly, tellurite is considered an inhibitor for gramnegative bacteria due to its high oxidizing ability, with tellurium compounds long been used as antimicrobial and therapeutic agents [7]. Conversely, Rhodobacter sphaeroides ( $R$. sphaeroides) cells could be exposed to concentrations up to $1 \mathrm{mg} \mathrm{ml}^{-1}$ ( $4 \mathrm{mM}$ ) of tellurite, intracellularly reducing it to $\mathrm{Te}^{0}$, and leading to the deposition of the metal in the cytoplasmic membrane with two enzymatic steps involved. Such findings shed light on the possible application of PNB for environmental remediation purposes.

Following this pioneering study, reports of PNB-metals interaction remained initially limited. In 1999, it was shown that the mechanism of $\mathrm{Ni}^{2+}$ transport and accumulation in Rhodospirillum rubrum ( $R$. rubrum) is related to the metabolism of $\mathrm{CO}$ oxidation [8]. Few years later, the mechanism of selenite reduction in $R$. sphaeroides was reported by Bebien et al. [9]. It was only in 2006 that the presence of a broad variety of metals $\left(\mathrm{Hg}^{2+}, \mathrm{Cu}^{2+}, \mathrm{Fe}^{2+}, \mathrm{Ni}^{2+}, \mathrm{Co}^{2+}\right.$, $\mathrm{MoO}_{4}{ }^{2-}$, and $\mathrm{CrO}_{4}{ }^{2-}$ ) was utilized to study the possible photosynthetic growth of the PNB R. sphaeroides mutant R26 in highly contaminated media [10]. The effects of various concentrations of the heavy metals on photoheterotropic growth rate, maximum cell densities, and lag-time were determined. As reported in Fig. 1, selected metals lead to considerably different effects, with $\mathrm{Hg}$ increasing lag-times, but resulting in no substantial changes in maximum cell densities for concentrations as high as $0.03 \mathrm{mM}$. Conversely, a particularly high resistance was observed for molybdate (no influence for concentrations as high as $60 \mathrm{mM}$ ). Co and Ni showed effects also on the photosynthetic apparatus, decreasing the number of pigment molecules obtained. An important aspect is that the ability to cope with the presence of the different heavy metals was not the result of an adaptation process, as bacteria were exposed to the metals without selection procedures.

The same group further investigated the interrelationship in the metabolism of $\mathrm{Mg}$ and $\mathrm{Co}$, revealing that high concentration of $\mathrm{Mg}$ reduced co-toxicity due to competitive uptake mechanisms [11]. By combining inductively coupled plasma atomic emission spectroscopy and attenuated total reflection Fourier transform infrared spectroscopy (ATR-FTIR), Italiano et al. further clarified the different mechanisms of $\mathrm{Co}, \mathrm{Ni}$, and $\mathrm{Mg}$ bioadsorption and bioaccumulation [12]. The study unveiled the role of carboxylate groups on the outer membrane of $R$. sphaeroides in binding metal cations, where $\mathrm{Co}^{2+}$ is competing with $\mathrm{Mg}^{2+}$ for the same binding groups. Furthermore, the coordination of cobalt ions binding to cellular components of $R$. sphaeroides was elucidated by X-ray absorption spectroscopy, differentiating between binding with soluble portions of the cells or the photosynthetic membranes [13]. Specifically, an extensive binding of cobalt ions to sulfolipids on the photosynthetic membrane was determined. Such findings were further supported by a later 


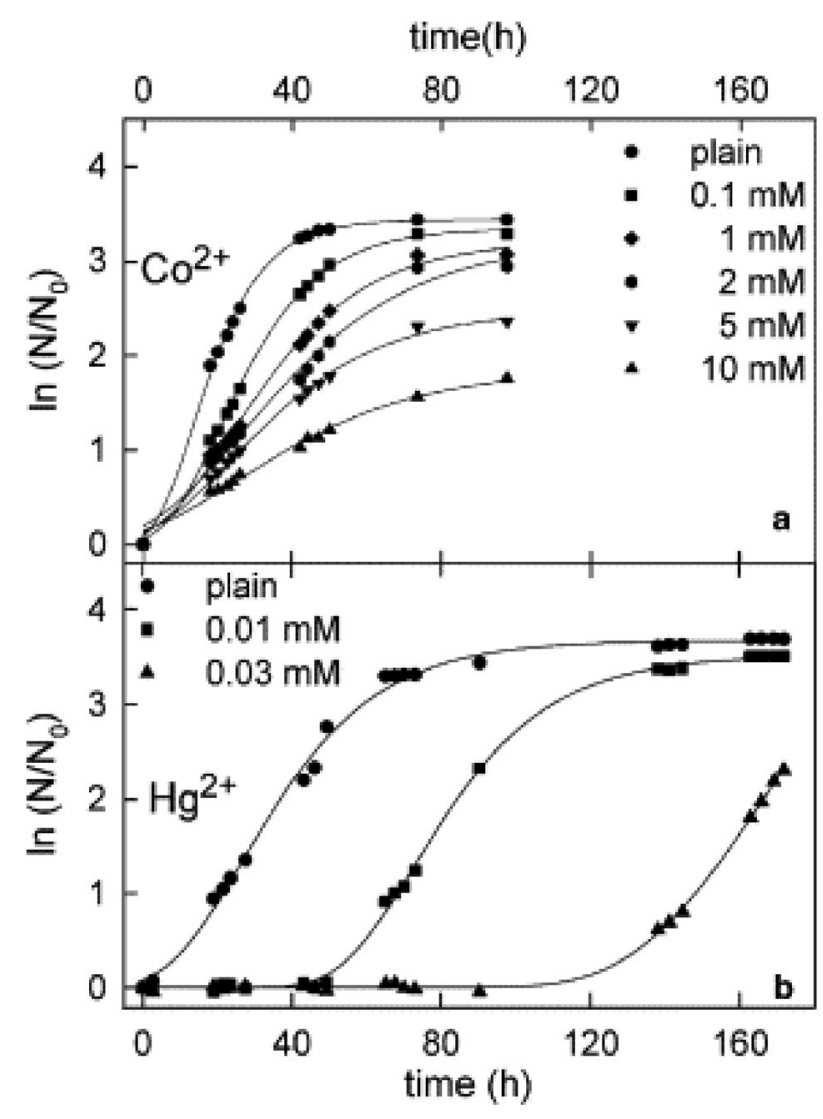

Fig. 1 Growth curves of the carotenoidless strain $R$. sphaeroides R26 obtained utilizing culture media supplemented with different concentrations of $\mathrm{Co}^{2+}(\mathbf{a})$ and $\mathrm{Hg}^{2+}(\mathbf{b})$. Reproduced with permission from Giotta et al. [10]. Copyrights 2005 Elsevier Ltd

study where thin-layer chromatography was coupled with matrix-assisted laser desorption ionization mass spectrometry (MALDI-MS), unveiling lipid alterations taking place after $\mathrm{Co}^{2+}$ and $\mathrm{CrO}_{4}{ }^{2-}$ exposure in $R$. sphaeroides [14]. $\mathrm{Co}^{2+}$ exposure resulted in a significant increase of sulfoquinovosyldiacylglycerols in the membrane lipids, while a decrease in the levels of phosphatidylglycerols was obtained. Interestingly, different analytical approaches were developed to utilize MALDI-MS for the determination of biotransformations in bacteriochlorophylls resulting from metal exposure [15].

Following studies were aimed to further characterize the interaction of cobalt ions with PNB at the gene expression level, unveiling internal reference gene for transcript analysis in presence of heavy metals stress [16], as well as changes in the relative amounts of proteins belonging to the photosynthetic apparatus [17]. Genomic and transcriptomic approaches showed that adaptation to Co presence proceeds through the activation of supplementary energetic metabolism processes [18].

Focusing on chromium contamination, the hexavalent form (Cr VI) is highly toxic and carcinogenic while also being very soluble in water. These characteristics, together with its extensive use in industries and human activities [19], make it one of the most critical contaminants for water environments. Italiano et al. unveiled the effects of chromate oxyanion on growth and protein expression, as well as cell dimension and morphology [20]. An important insight is that cell cultures were able to completely reduce $0.2 \mathrm{mM}$ chromate to the less toxic $\mathrm{Cr}$ III within $80-90 \mathrm{~h}$ from light exposure. The largest contribution to chromate reduction was assigned to the soluble intracellular fraction, suggesting that the oxyanions are transported into the cytoplasm for being detoxified. A significant cell elongation was also obtained for the bacteria exposed to chromate as shown in Fig. 2.

The detailed effects of mercury on the photosynthetic apparatus of PNB were investigated by Asztalos et al. showing that $\mathrm{Hg}^{2+}$ significantly affected the electron transport sites of the reaction center in $R$. sphaeroides $\left(\mathrm{Q}_{\mathrm{A}}\right.$ and $\mathrm{Q}_{\mathrm{B}}$ sites) [21]. Conversely, the light-harvesting system and the $b c_{1}$ complex are less affected by the presence of $\mathrm{Hg}^{2+}$. In recent years, Kis et al. studied the stoichiometry and kinetics of $\mathrm{Hg}$ uptake by various PNB (Rubrivivax gelatinous (R. gelatinous), R. rubrum, and R. sphaeroides 2.4.1) [22]. Interestingly, two well-separated kinetic steps were determined for $\mathrm{Hg}$ uptake, with a fast initial adsorption to the cell surface and a passive, non-specific diffusion through the cell membrane, followed by a slower and energy-consuming transport mechanism. $\mathrm{Ca}^{2+}$ channel could be determined as actively involved in the transport, which was magnified under illumination. $\mathrm{pH}$ variations also influenced $\mathrm{Hg}$ uptake, as shown in Fig. 3, with decreasing rates for both acidic or alkaline $\mathrm{pH}$ values. It should also be noted that the organization of cells from planktonic to biofilm reduced mercury toxicity for the cells.

Finally, Grégoire and Poulain showed that $R$. capsulatus, $R$. sphaeroides, and Rhodopseudomonas palustris ( $R$. palustris) were capable of utilizing $\mathrm{Hg}^{2+}$ as an electron sink to maintain their redox homeostasis, resulting in the production of the less toxic $\mathrm{Hg}^{0}$ [23]. Specifically, under photoheterotrophic growth conditions (using butyrate or acetate as carbon sources), all the strains where capable of utilizing $\mathrm{Hg}^{2+}$ present in the growth medium in sub-lethal concentrations up to $200 \mathrm{nM}$, indicating that $\mathrm{Hg}^{2+}$ reduction plays a physiological role when excess reducing power is available.

As mentioned in the introduction, metal ions are critical non only for PNB, and various studies were performed also to unveil the mechanisms of metal ions transport and regulation in oxygenic photosynthetic microorganisms such as cyanobacteria, for which we refer the reader to other literature [24-27]. Particularly, high concentrations of mercury were shown to have detrimental effects also on the photosynthetic apparatus of cyanobacteria, specifically on photosystem II (PSII) [24]. A cascade inhibition mechanism 

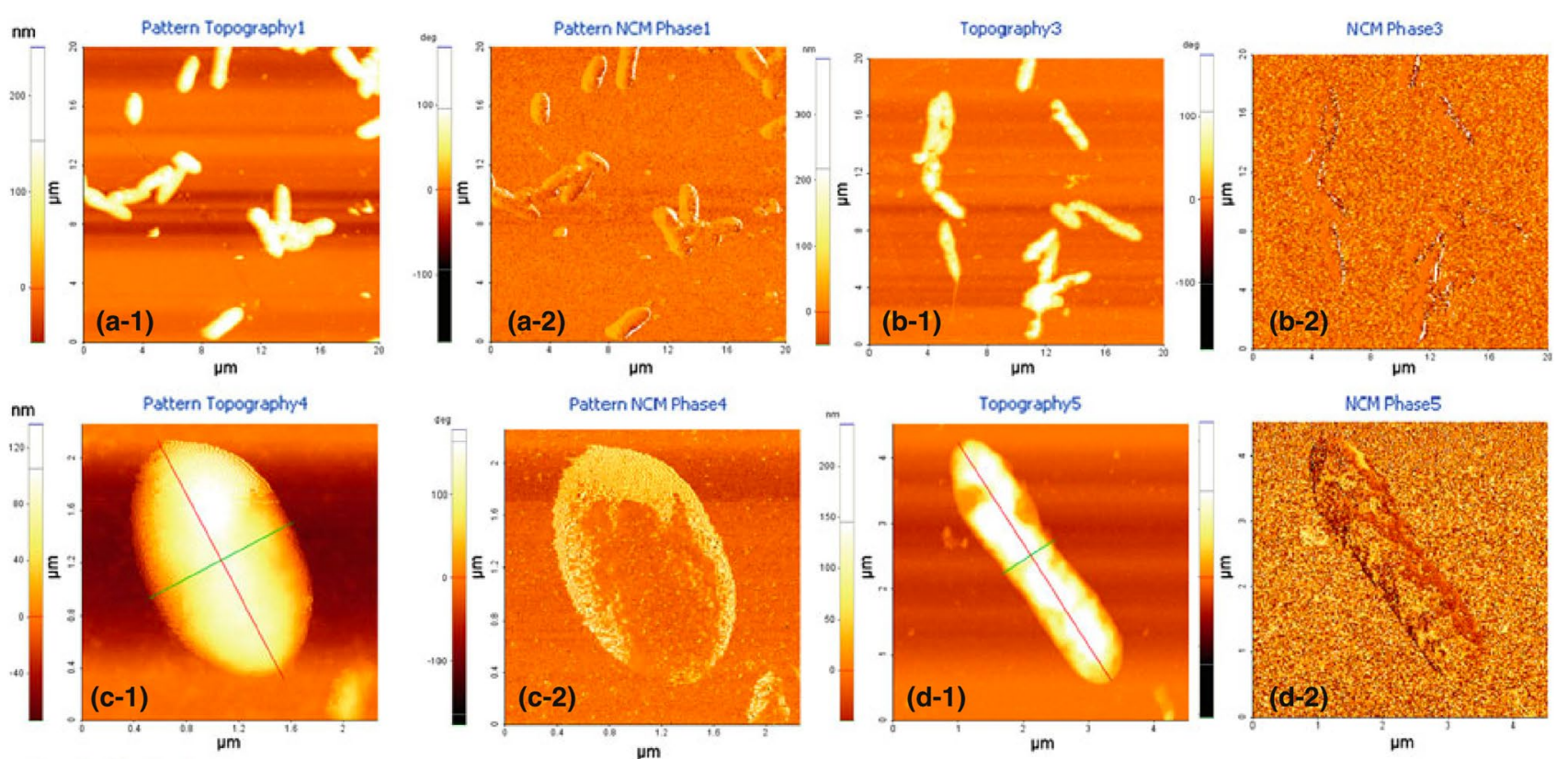

Fig. 2 Atomic force topographic image of $R$. sphaeroides cells $\left(10^{8} \mathrm{CFU} \mathrm{ml} \mathrm{m}^{-1}\right)$ grown in control conditions (a-1) and corresponding phase image (a-2). Atomic force topographic image of $R$. sphaeroides cells $\left(10^{8} \mathrm{CFU} \mathrm{ml}{ }^{-1}\right)$ grown in a medium with $0.2 \mathrm{mM}$ chromate (b1) and corresponding phase image (b-2). Atomic force topographic image of a single $R$. sphaeroides cell grown in control conditions (c-

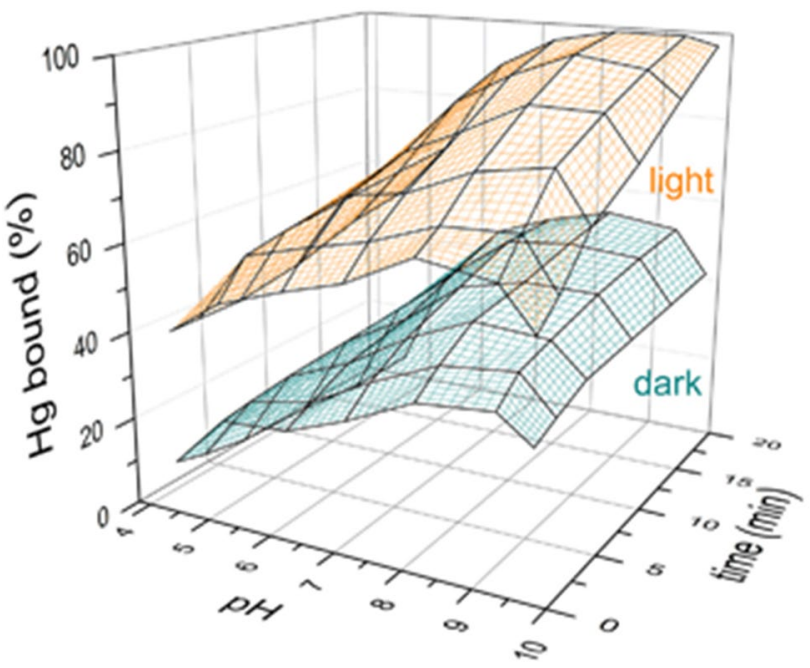

Fig. 3 Quasi-3D representation of the mercury uptake of $R$. gelatinosus cells in the dark (green surface) and under illumination (orange surface) as the functions of mercury treatment duration and $\mathrm{pH}$ of the culture. Reproduced with permission from Kis et al. [22]. Copyright 2017, Springer Science + Business Media Dordrecht

was determined for $\mathrm{Cd}^{2+}$ on the photosynthetic apparatus of the cyanobacterium, Synechocystis PCC 6803, initially inhibiting the dark phase of photosynthesis to following,
1) and corresponding phase image (c-2). Atomic force topographic image of a single $R$. sphaeroides cell grown in $0.2 \mathrm{mM}$ chromate poisoned medium (d-1) and corresponding phase image (d-2). Adapted with permission from Italiano et al. [20]. Copyright 2012, Springer Science Business Media, LLC

in the presence of light, lead to an elevated excitation pressure on PSII impairing its function [26].

\section{PNB in environmental monitoring and remediation}

\subsection{Metal removal}

After the capability of PNB to cope with high concentrations of heavy metals was unveiled, the possibility to utilize these organisms to harvest, detoxify, and remove toxic compounds by bioadsorption and bioaccumulation raised interest. Buccoleri et al. reported the relatively high sequestration of $\mathrm{Co}^{2+}$ and $\mathrm{CrO}_{4}{ }^{2-}$ in biomass obtained during the photosynthetic growth of $R$. sphaeroides strain R26.1 [28]. A few years later, Vílchez et al., utilized a biofilm-based "biofilter" capable of removing over $99 \%$ of $\mathrm{Pb}$ (II) even after several months of operation. Interestingly, analysis of the DNA extracted from the biofilm revealed that the majority of the species belonged to the genus Rhodobacter [29]. Recently, the excellent capability of $R$. sphaeroides to remove $\mathrm{Pb}$ was reported by $\mathrm{Su}$ et al., who compared the removal efficiency of $\mathrm{Pb}$, $\mathrm{Hg}$, and $\mathrm{Cd}$ from aqueous solutions [30]. R. sphaeroides SC01 achieved $98 \%$ removal of $\mathrm{Pb}$ in solutions containing $160 \mathrm{mg} \mathrm{L}^{-1}$ of $\mathrm{Pb}^{2+}$, showing a remarkably higher resistance 


\section{light}

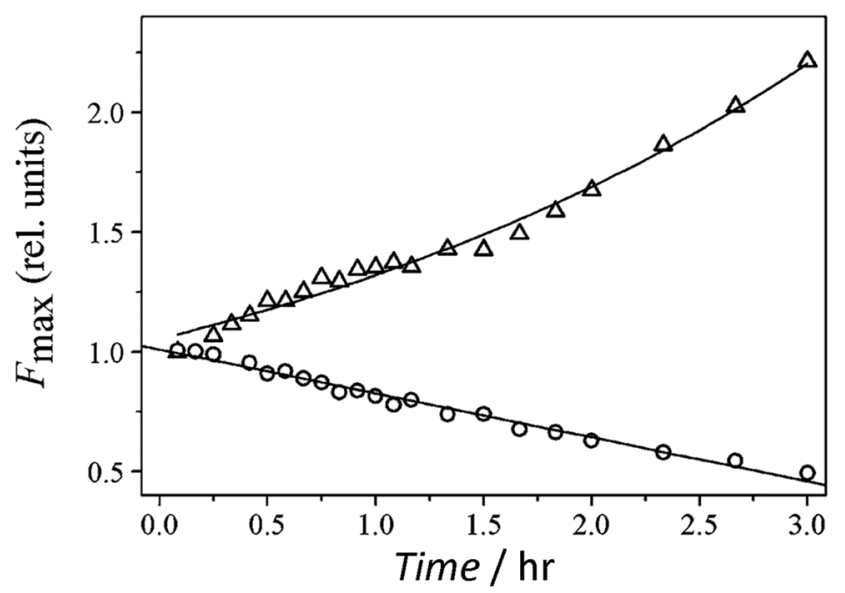

Fig. 4 Variation of Fmax in control cells (not exposed to $\mathrm{Hg}^{2+}$ ) and after initial exposure to $26 \mu \mathrm{M} \mathrm{Hg}^{2+}$ both in light and dark conditions. Adapted from Asztalos et al. [34] with permission from the European

to $\mathrm{Pb}$ compared to $\mathrm{Hg}$ and $\mathrm{Cd}$. Under $\mathrm{Pb}$ stress, a lower accumulation of reactive oxygen species $\left(\mathrm{O}_{2}^{-}\right.$and $\left.\mathrm{H}_{2} \mathrm{O}_{2}\right)$ was obtained, together with higher enzymatic antioxidant activity, indicating that the strain has both high resistance and high removal efficiency for $\mathrm{Pb}$ through regulating the antioxidant system and the formation of precipitates. Finally, the isolation of three $\mathrm{Hg}$-resistant PNB (Afifella marina SSS2-1 and SSW15-1, and Rhodovulum sulfidophilum SRW1-5) was utilized to reduce mercury contamination in shrimp ponds by Mukkata et al. [31] The bacterial cells performed $\mathrm{Hg}$ volatilization thanks to the activity of the mercuric reductase enzyme.

It should be noted that PNB were investigated also for soil bioremediation, successfully showing that $R$. sphaeroides could be employed in soil contaminated with both $\mathrm{Pb}$ and $\mathrm{Cd}$, achieving a reduction of their accumulation in roots and leaf between 25 and $60 \%$ [32, 33].

\subsection{Metal monitoring}

In addition to metal removal, the studies of PNB -metals interactions paved the way also for the development of different approaches for the early monitoring of heavy metals contamination. In this contest, Asztalos et al. showed that, after exposing $R$. sphaeroides $\mathrm{R} 26.1$ cells to $\mathrm{Hg}$ during their growth (both under photosynthetic conditions and not), fluorescence induction (sudden dark-light transition) allowed fast determination of $\mathrm{Hg}$ presence thanks to the decrease of both the maximum and variable fluorescence [34]. It is worth underlining that the variation in both parameters was greater for cells kept in light conditions, as shown in Fig. 4.

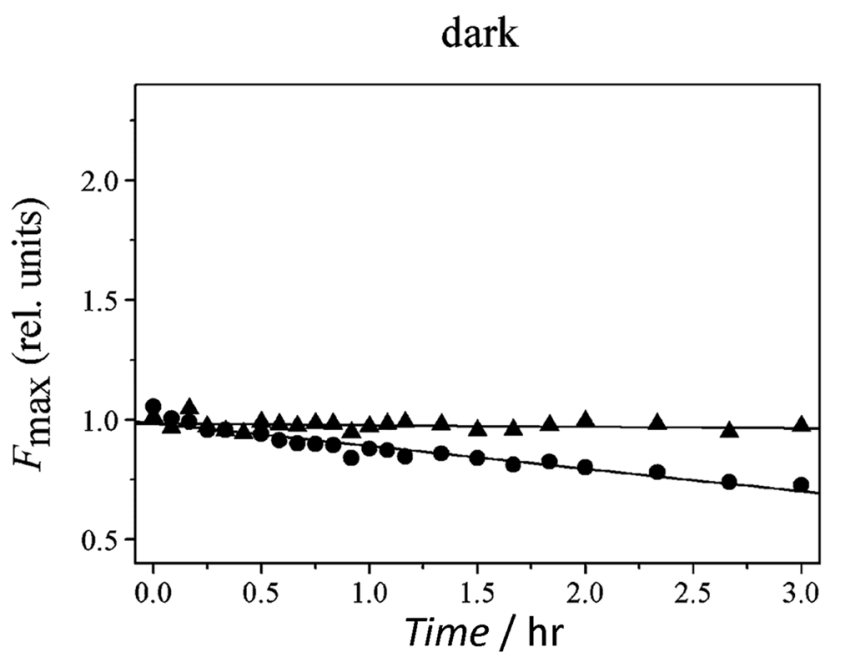

Society for Photobiology, the European Photochemistry Association, and the Royal Society of Chemistry

Accordingly, the results showed that $\mathrm{Hg}$ acts by inhibiting the photosynthetic apparatus of the bacteria.

In a later study, Kis et al. compared three different strains of PNB (R. gelatinous, $R$. rubrum, and $R$. sphaeroides) for monitoring $\mathrm{Hg}, \mathrm{Cr}$, and $\mathrm{Pb}$ stresses through steady-state absorption spectra and fluorescence induction [35]. The various strains showed remarkable differences in the sensitivity to the three metal stresses, with $R$. gelatinous tolerating orders of magnitude higher $\mathrm{Hg}$ concentrations $(200 \mu \mathrm{M})$ while having higher drops in absorbance and maximum fluorescence resulting from exposure to $\mathrm{Pb}$ compared to $R$. rubrum. Furthermore, it was shown that $\mathrm{Pb}^{2+}$ ions in a broad range of concentrations perform high penetration in the cell wall and caused a significant destruction of the antenna complexes.

\subsection{Metals \& bio-nanofactories}

The capability of PNB to withstand high metal concentrations was utilized also to combine the removal of such metals to the synthesis of nanoparticles, thus obtaining bio-nanofactories. Bai et al. reported that exposing $R$. sphaeroides cells to high concentrations $(2.5 \mathrm{mM})$ of $\mathrm{ZnSO}_{4}$ allowed performing the synthesis of the nanoparticles of the semiconductor $\mathrm{ZnS}$ [36]. Specifically, the biosynthesis was performed during the growth of the bacterial cells, under neutral $\mathrm{pH}$ and $30^{\circ} \mathrm{C}$, and allowed to almost completely remove soluble zinc in about $30 \mathrm{~h}$. The duration of the incubation influenced the dimension of the nanoparticles, with diameters ranging from 4 to $105 \mathrm{~nm}$ for incubation times of 25 and $45 \mathrm{~h}$, respectively. $\mathrm{Li}$ et al. [37] expanded the possibilities of utilizing PNB as bio-nanofactories showing that selenite $\left(\mathrm{SeO}_{3}{ }^{-2}\right)$ could 
Fig. 5 Transmission electron microscopy micrographs of $R$. sphaeroides cells without (a) and with exposure to $10 \mu \mathrm{M} \mathrm{Au}(\mathrm{III})$ (b) revealing a significant cell elongation after exposure to $\mathrm{Au}(\mathrm{III})$. Extracellular aggregates of gold nanoparticles shown at two different magnifications (c and d). Reproduced from Italiano et al. [38]. Copyright 2018, Elsevier
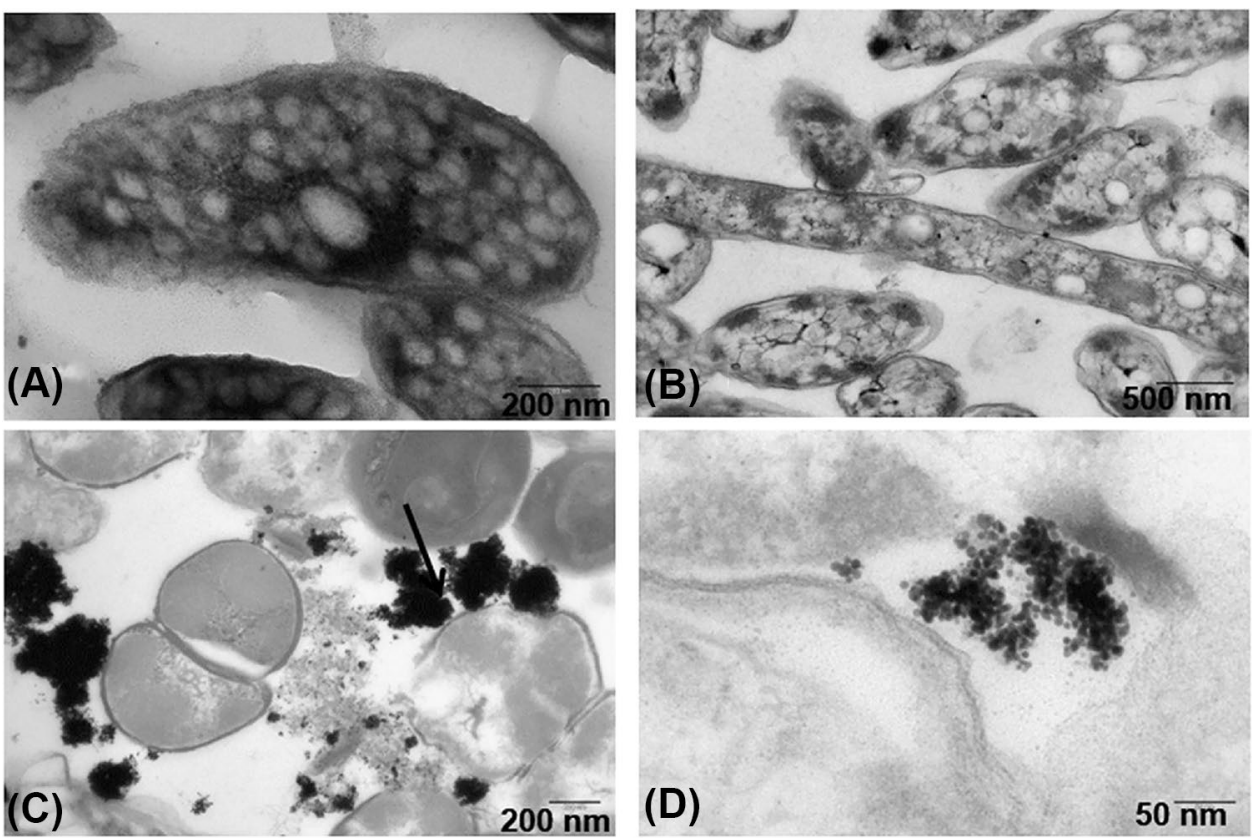

(D)

$50 \overline{\mathrm{nm}}$ be reduced to red elemental selenium, obtaining nanoparticles with diameters between 80 and $200 \mathrm{~nm}$ on the surface of $R$. palustris cells. Later, Italiano et al. [38] reported the extracellular synthesis of gold nanoparticles utilizing $R$. sphaeroides strain R26. When the bacteria were exposed to $\mathrm{Au}(\mathrm{III})$ under photosynthetic growth, gold nanoparticles with an average size of $10 \mathrm{~nm}$ were obtained, as shown by the transmission electron microscopy micrographs of Fig. 5.

Different mechanisms of nanoparticle synthesis (i.e., intracellular or extracellular production) would strongly affect the following purification and nanoparticle harvesting procedures required. It should be noted that the detailed mechanisms of nanoparticles synthesis have yet to be elucidated for several organisms, and we refer the reader to a recent review on this topic for the most updated literature [39]. Briefly, if nanoparticles were biosynthetized in the intracellular space, cell lysis would be required to harvest them for practical applications; various approaches are available, including the use of ultrasonication, heat treatments, detergents and salts [40, 41]. If nanoparticles assemble on the cell surface, their harvesting might be attained by mild centrifugation, avoiding cell death. Furthermore, it has been recently reported that some organisms act as bio-nanofactories using extracellularly secreted enzymes, thus overruling cell lysis or centrifugation, with the nanoparticles obtained directly in the supernatant and easily recovered by centrifugation [42]. Due to the high relevance of bio-nanofactories, more studies are needed to shed light on these exciting processes.

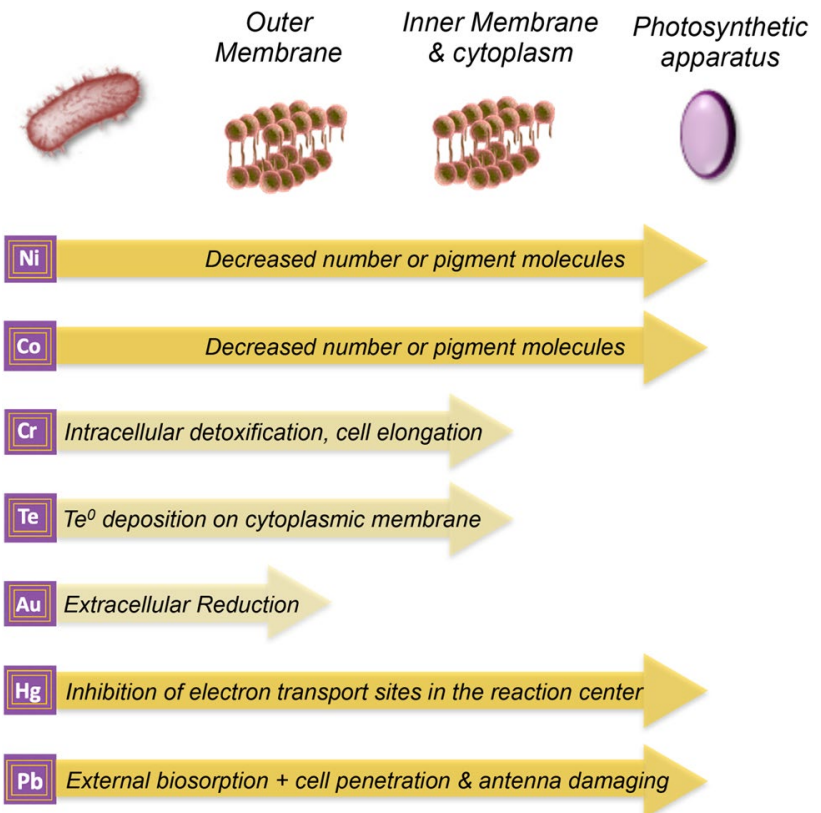

Scheme 1. Effects of the most studied metal ions (ordered by atomic weight) on PNB. The arrow's length refers to the capability of the metal ions to cross or not the outer membrane. The arrows reaching the photosynthetic apparatus indicate the capability of the metal ions to affect the components of the photosynthetic apparatus

The effects of the various metal ions on PNB discussed in the previous sections have been summarized in Scheme 1. 


\section{From knowledge to future directions: PNB application in biohybrid electrochemical systems}

As extensively discussed, the implications of PNB-metals interactions can be critical for environmental remediation and monitoring purposes. In this context, coupling intact PNB cells and electrode surfaces represents an intriguing possibility, which enables the development of biohybrid electrochemical systems (BES). Specifically, the establishment of an electrochemical communication between the biotic and abiotic components would introduce an interface to selectively control, or facilitate, a selected metabolism to enhance the removal of pollutants. Additionally, it has been reported that when bacteria are exposed to solutions containing contaminants, the flow of electrons between the biological catalyst and the abiotic electrode surface might be affected, paving the way to the development of microbial electrochemical biosensors [43]. In such biosensors, the presence of contaminants can be determined "on-line", based on variations in the current response, thus enabling the early and continuous monitoring of toxic compounds. However, while model electroactive bacteria have been extensively studied to clarify the electrochemical processes taking place at the biotic/abiotic interface (with ongoing debates on the electron transfer mechanisms also for these model organisms) [44, 45], the possibility to establish an electrochemical communication between PNB and electrodes has been reported relatively recently [46]. In an early report, Xing et al. [47] showed that the PNB $R$. palustris DX-1 could be isolated from the anode of a microbial fuel cell operating for over 3 months. The isolated strain showed good electron transfer capabilities with the abiotic electrode surface. However, the detailed mechanisms utilized by the bacteria to accomplish extracellular electron transfer was not determined, with biofilm formation that seemed to play a major role. Later, PNB have been "wired" to electrodes surfaces utilizing both osmium-based and quinone-based artificial redox mediators to facilitate the extracellular electron transfer. A scheme of the artificial extracellular mediated electron transfer process is reported in Fig. 6, with examples of various approaches utilized in the literature [48-51]. To date, studies of PNB biohybrid electrochemical systems have been focused on biophotocurrent production, thus on the required "wiring" of the biotic components with the electrode surface, with only a few reports focusing on how the presence of environmental stresses influence the photoexcited electron transfer and biophotoelectrocatalysis [52, 53]. Specifically, it was shown that under prolonged salt stress a decreased expression of genes involved in the photosynthetic electron transfer chain of $R$. capsulatus cells is obtained, leading to an altered interaction between the exogenous diffusible redox mediator $p$-benzoquinone and the photosynthetic apparatus. Such alteration resulted in decreased biophotocurrent generation and higher loss of biophotoelectrocatalysis over alternated light/dark cycles compared to cells not exposed to salinity [52].

It is clear that the use of such BES for environmental monitoring and remediation remains to be explored, and research efforts should be directed toward this topic. Furthermore, it should be noted that biohybrid electrochemical systems could be used also as a tool to elucidate the mechanisms of metal-bacteria interaction while being utilized in the biohybrid system. In this context, a biohybrid electrochemical system employing exogenous quinone molecules has been recently reported by Borghese et al. [54] to demonstrate how harvesting photoexcited electrons from the photosynthetic apparatus of Rhodobacter capsulatus enables reducing the toxic oxyanion tellurite $\left(\mathrm{TeO}_{3}{ }^{2-}\right)$ outside the cell membranes of the bacteria.

\section{Conclusions and future perspectives}

The outstanding tolerance of PNB toward high metal concentrations has attracted the interest of several research groups, and the scientific community achieved a comprehensive understanding of the mechanisms of metal uptake and reduction. These findings resulted in the application of PNB for metal ions removal and monitoring in various environments. As discussed in the review, and further summarized in Table 1, PNB can withstand and remove a broad variety of metal ions from both aqueous and soil environments, while enabling their preliminary monitoring. Biofilters and fluorescence-based biosensors have been shown as a practical application of PNB -metal ions interactions. To fully explore these capabilities, a possible direction to follow is the coupling of these organisms with abiotic electrodes, to obtain biohybrid electrochemical systems. The concept of BES has been shown, and the most recent advancements in PNB photobioelectrochemistry have been presented, with the architectures utilized to actively "wire" intact bacterial cells to the electrode. Rationally controlling the interface between these photosynthetic organisms and the electrode could lead to selectively removing and monitoring metal ions. However, the coupling of intact cells with abiotic electrodes remains challenging due to the location of their photosynthetic apparatus deeply buried in the inner membrane. The recent advancements in the field of artificial electron mediation approaches employed with other photosynthetic organisms and apparatuses (i.e., rational design of conductive/ redox polymer and engineering of the biotic/abiotic interface) [55-57], together with synthetic biology solutions to 
(A)

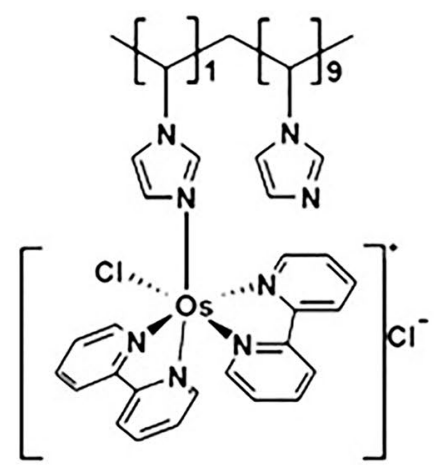

(B)

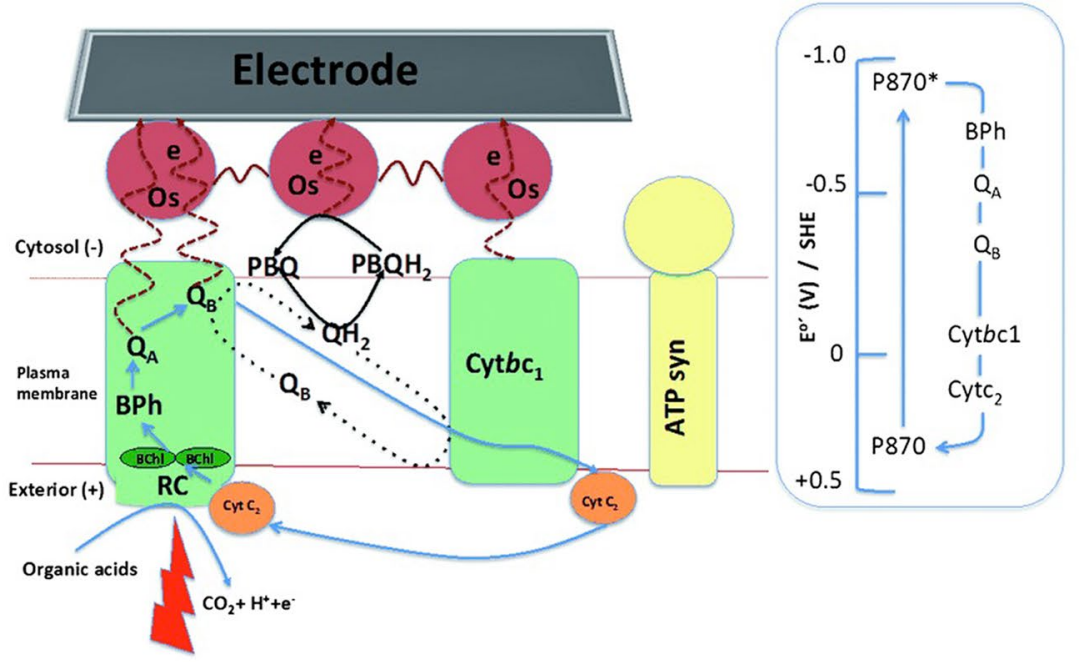

(C)

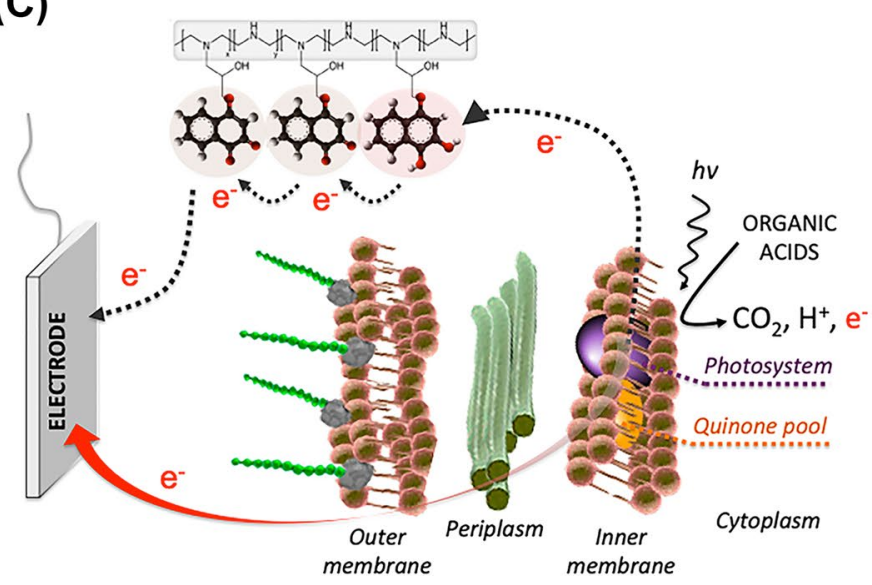

Fig. 6 a Structural representation of the Os-redox polymer utilized by Hasan et al. [48]. Reproduced with permission from Hasan et al. [48]. Copyright 2012, Elsevier B.V. b Scheme of the biophotoelectrochemical process taking place in the Os-mediated biohybrid photoanode. The artificial redox mediating system (Os-polymer) might wire the photosynthetic apparatus of $R$. capsulatus through the $\mathrm{Q}_{\mathrm{A}}$ or $\mathrm{Q}_{\mathrm{B}}$ active sites, the quinone pool (PBQ-PBQH $\left.{ }_{2}\right)$, or Cyt $b c_{1}$. Reproduced with permission from Hasan et al. [49]. Copyright 2015, Wiley-VCH Verlag GmbH \& Co. KGaA, Weinheim. c Scheme of the biophoto-

facilitate the transfer of photoexcited electrons [58], could lead to groundbreaking achievements for PNB biohybrid electrochemical systems. The reader interested in a thorough review on how to upgrade photobioelectrochemical systems is referred to a recent work [59]. Computational electrochemical process taking place in the quinone-mediated biohybrid photoanode. Black dashed arrows indicate the electron transfer process taking place through the quinone redox centers of the polymer, the red arrow represents the direct extracellular electron transfer requiring to cross both the inner and the outer membranes, in addition to the periplasm layer. Reproduced with permission from Grattieri et al. [51]. Copyright 2020, Wiley-VCH Verlag GmbH \& Co. KGaA, Weinheim

approaches are another powerful tool that should be utilized to reach a mechanistic understanding of biohybrid electrochemical systems and rationally designing them for metal ions removal and monitoring [60].

In conclusion, the scientific community is called to address critical research challenges to fully exploit the possibilities enabled by the interaction of photosynthetic PNB and metal ions, but enthralling applications are at the horizon for this technology. 
Table 1 Summary of the works dealing with the interactions of metals and PNB discussed in this review

\begin{tabular}{|c|c|c|c|}
\hline Metals & Organisms & Objective of the study/Main finding & References \\
\hline $\mathrm{Te}$ & R. sphaeroides & Intracellular reduction & {$[6]$} \\
\hline $\mathrm{Te}$ & R. capsulatus & Extracellular reduction with exogenous quinones & {$[54]$} \\
\hline $\mathrm{Ni}$ & R. rubrum & Mechanism of $\mathrm{Ni}^{2+}$ transport $\&$ accumulation & [8] \\
\hline $\begin{array}{c}\mathrm{Ni}, \mathrm{Hg}, \mathrm{Cu}, \mathrm{Fe}, \\
\mathrm{Co}, \mathrm{Mo}, \mathrm{Cr}\end{array}$ & R. sphaeroides & Influence of highly contaminated media on photosynthetic growth & {$[10]$} \\
\hline $\mathrm{Mg}$, Co & R. sphaeroides & Uptake mechanisms and co-toxicity & {$[11]$} \\
\hline $\mathrm{Mg}, \mathrm{Co}, \mathrm{Ni}$ & R. sphaeroides & Bioadsorption and bioaccumulation mechanisms & {$[12]$} \\
\hline Co & R. sphaeroides & Binding mechanisms & [13] \\
\hline $\mathrm{Co}, \mathrm{Cr}$ & R. sphaeroides & Bioalterations due to metal exposure & {$[14]$} \\
\hline Co & R. sphaeroides & Determination of reference gene for transcript analysis & [16] \\
\hline Co & R. sphaeroides & Variations in genes expression & {$[17]$} \\
\hline Co & R. sphaeroides & Proteomics for adaptation mechanism & {$[18]$} \\
\hline $\mathrm{Cr}$ & R. sphaeroides & Cell growth and morphology. Changes in protein expression & {$[20]$} \\
\hline $\mathrm{Co}, \mathrm{Cr}$ & R. sphaeroides & Bioadsorption and bioaccumulation & {$[28]$} \\
\hline $\mathrm{Hg}$ & R. sphaeroides & Metal effects on the photosynthetic apparatus & {$[21]$} \\
\hline $\mathrm{Hg}$ & R. gelatinous, $R$. rubrum, $R$. sphaeroides & Stoichiometry and kinetic of uptake & {$[22]$} \\
\hline $\mathrm{Hg}$ & R. capsulatus, $R$. sphaeroides, $R$. palustris & $\mathrm{Hg}^{2+}$ as an electron sink for redox homeostasis & [23] \\
\hline $\mathrm{Hg}$ & R. sphaeroides & Metal monitoring & {$[34]$} \\
\hline $\mathrm{Hg}$ & A. marina, $R$. sulfidophilum & Metal removal & {$[31]$} \\
\hline $\mathrm{Hg}, \mathrm{Pb}, \mathrm{Cr}$ & R. gelatinous, $R$. rubrum, $R$. sphaeroides & Metal monitoring & {$[35]$} \\
\hline $\mathrm{Pb}$ & genus Rhodobacter & Biofilm-based "biofilter" & [29] \\
\hline $\mathrm{Pb}, \mathrm{Hg}, \mathrm{Cd}$ & R. sphaeroides & Metal removal & {$[30]$} \\
\hline $\mathrm{Cd}$ & R. sphaeroides & Soil remediation & {$[32]$} \\
\hline $\mathrm{Pb}$ & R. sphaeroides & Soil remediation & {$[33]$} \\
\hline $\mathrm{Zn}$ & R. sphaeroides & Bio-nanofactories & {$[36]$} \\
\hline $\mathrm{Se}$ & R. palustris & Bionanofactories & {$[37]$} \\
\hline $\mathrm{Au}$ & R. sphaeroides & Bio-nanofactories & {$[38]$} \\
\hline
\end{tabular}

Acknowledgements Matteo Grattieri would like to acknowledge the funding from Fondazione CON IL SUD, Grant "Brains to South 2018", project number 2018-PDR- 00914. This work was partly funded by PON Energy for TARANTO project n. ARS01_00637.

\section{Declarations}

Conflict of Interest The authors declare no conflicting nor competing interests.

Open Access This article is licensed under a Creative Commons Attribution 4.0 International License, which permits use, sharing, adaptation, distribution and reproduction in any medium or format, as long as you give appropriate credit to the original author(s) and the source, provide a link to the Creative Commons licence, and indicate if changes were made. The images or other third party material in this article are included in the article's Creative Commons licence, unless indicated otherwise in a credit line to the material. If material is not included in the article's Creative Commons licence and your intended use is not permitted by statutory regulation or exceeds the permitted use, you will need to obtain permission directly from the copyright holder. To view a copy of this licence, visit http://creativecommons.org/licenses/by/4.0/.

\section{References}

1. Madigan, M. T., \& Jung, D. O. (2009). An overview of purple bacteria: Systematics, physiology, and habitats. In C. N. Hunter, F. Daldal, M. C. Thurnauer, \& J. T. Beatty (Eds.), The purple phototrophic bacteria (pp. 1-15). Springer.

2. Allen, J. P., \& Williams, J. C. (1998). Photosynthetic reaction centers. FEBS Letters, 438, 5-9.

3. Drews, G., and Imhoff, J. F. (1991). Phototrophic purple bacteria. In J. M. Shively, L. L. Barton (Eds.) Variations in autotrophic life (pp. 51-97). Academic Press Limited.

4. Sasikala, C., and Ramana, C. V. (1997). Biodegradation and metabolism of unusual carbon compounds by anoxygenic phototrophic bacteria. In R. K. Poole (Ed.) Adv. Microb. Physiol. (pp. 339-377). Academic Press.

5. Loutet, S. A., Chan, A. C. K., Kobylarz, M. J., Verstraete, M. M., Pfaffen, S., Ye, B., Arrieta, A. L., and Murphy, M. E. P. (2015). The fate of intracellular metal ions in microbes. In J. O. Nriagu, E. P. Skaar (Eds.) Trace Metals and Infectious Diseases (pp. 39-56). The MIT Press.

6. Moore, M. D., \& Kaplan, S. (1992). Identification of intrinsic high-level resistance to rare-earth oxides and oxyanions in members of the class proteobacteria: Characterization of tellurite, selenite, and rhodium sesquioxide reduction in rhodobacter sphaeroides. Journal of Bacteriology, 174, 1505-1514. 
7. Taylor, D. E. (1999). Bacterial tellurite resistance. Trends in Microbiology, 7, 111-115.

8. Watt, R. K., \& Ludden, P. W. (1999). $\mathrm{Ni}^{2+}$ Transport and Accumulation in Rhodospirillum rubrum. Journal of Bacteriology, 181, 4554-4560.

9. Bebien, M., Chauvin, J.-P., Adriano, J.-M., Grosse, S., \& Verméglio, A. (2001). Effect of selenite on growth and protein synthesis in the phototrophic bacterium Rhodobacter sphaeroides. Applied and Environment Microbiology, 67, 4440-4447.

10. Giotta, L., Agostiano, A., Italiano, F., Milano, F., \& Trotta, M. (2006). Heavy metal ion influence on the photosynthetic growth of Rhodobacter sphaeroides. Chemosphere, 62, 1490-1499.

11. Giotta, L., Italiano, F., Buccolieri, A., Agostiano, A., Milano, F., \& Trotta, M. (2008). Magnesium chemical rescue to cobalt -poisened cells from Rhodobacter sphaeroides. In J. F. Allen, E. Ganntt, J. H. Golbeck, B. Osmond (Eds.) Photosynthesis. Energy from the Sun:14th International Congress on Photosynthesis (pp. 1455-1458). Springer.

12. Italiano, F., Buccolieri, A., Giotta, L., Agostiano, A., Valli, L., Milano, F., \& Trotta, M. (2009). Response of the carotenoidless mutant Rhodobacter sphaeroides growing cells to cobalt and nickel exposure. International Biodeterioration \& Biodegradation, 63, 948-957.

13. Belviso, B. D., Italiano, F., Caliandro, R., Carrozzini, B., Costanza, A., \& Trotta, M. (2013). Cobalt binding in the photosynthetic bacterium $R$. sphaeroides by X-ray absorption spectroscopy. BioMetals, 26, 693-703.

14. Calvano, C. D., Italiano, F., Catucci, L., Agostiano, A., Cataldi, T. R. I., Palmisano, F., \& Trotta, M. (2013). The lipidome of the photosynthetic bacterium Rhodobacter sphaeroides R26 is affected by cobalt and chromate ions stress. BioMetals, 27, 65-73.

15. Calvano, C. D., Ventura, G., Trotta, M., Bianco, G., Cataldi, T. R. I., \& Palmisano, F. (2016). Electron-transfer secondary reaction matrices for MALDI MS analysis of bacteriochlorophyll a in Rhodobacter sphaeroides and its zinc and copper analogue pigments. Journal of The American Society for Mass Spectrometry, $28,125-135$.

16. Losurdo, L., Italiano, F., Trotta, M., Gallerani, R., Luigi, R. C., $\&$ Leo, F. D. (2010). Assessment of an internal reference gene in Rhodobacter sphaeroides grown under cobalt exposure. Journal of Basic Microbiology, 50, 302-305.

17. Italiano, F., D’Amici, G. M., Rinalducci, S., De Leo, F., Zolla, L., Gallerani, R., Trotta, M., \& Ceci, L. R. (2011). The photosynthetic membrane proteome of Rhodobacter sphaeroides $\mathrm{R}-26.1$ exposed to cobalt. Research in Microbiology, 162, 520-527.

18. Volpicella, M., Costanza, A., Palumbo, O., Italiano, F., Claudia, L., Placido, A., Picardi, E., Carella, M., Trotta, M., \& Ceci, L. R. (2014). Rhodobacter sphaeroides adaptation to high concentrations of cobalt ions requires energetic metabolism changes. FEMS Microbiology Ecology, 88, 345-357.

19. Economou-Eliopoulos, M., Megremi, I., \& Vasilatos, C. (2011). Factors controlling the heterogeneous distribution of $\mathrm{Cr}(\mathrm{VI})$ in soil, plants and groundwater: Evidence from the Assopos basin, Greece. Geochemistry, 71, 39-52.

20. Italiano, F., Rinalducci, S., Agostiano, A., Zolla, L., De Leo, F., Ceci, L. R., \& Trotta, M. (2012). Changes in morphology, cell wall composition and soluble proteome in Rhodobacter sphaeroides cells exposed to chromate. BioMetals, 25, 939-949.

21. Asztalos, E., Sipka, G., Kis, M., Trotta, M., \& Maróti, P. (2012). The reaction center is the sensitive target of the mercury(II) ion in intact cells of photosynthetic bacteria. Photosynthesis Research, 112, 129-140.

22. Kis, M., Sipka, G., \& Maróti, P. (2017). Stoichiometry and kinetics of mercury uptake by photosynthetic bacteria. Photosynthesis Research, 132, 197-209.
23. Grégoire, D. S., \& Poulain, A. J. (2016). A physiological role for HgII during phototrophic growth. Nature Geoscience, 9, 121-125.

24. Lu, C. M., Chau, C. W., \& Zhang, J. H. (2000). Acute toxicity of excess mercury on the photosynthetic performance of cyanobacterium, $S$. platensis - assessment by chlorophyll fuorescence analysis. Chemosphere, 41, 191-196.

25. Tůmová, E., \& Sofrová, D. (2002). Response of intact cyanobacterial cells and their photosynthetic apparatus to $\mathrm{Cd}^{2+}$ ion treatment. Photosynthetica, 40, 103-108.

26. Tóth, T., Zsiros, O., Kis, M., Garab, G., \& Kovács, L. (2012). Cadmium exerts its toxic effects on photosynthesis via a cascade mechanism in the cyanobacterium, synechocystis PCC 6803. Plant, Cell \& Environment, 35, 2075-2086.

27. Huertas, M., López-Maury, L., Giner-Lamia, J., Sánchez-Riego, A., \& Florencio, F. (2014). Metals in cyanobacteria: Analysis of the copper, nickel, cobalt and arsenic homeostasis mechanisms. Life, 4, 865-886.

28. Buccolieri, A., Italiano, F., Dell'Atti, A., Buccolieri, G., Giotta, L., Agostiano, A., Milano, F., \& Trotta, M. (2006). Testing the photosynthetic bacterium Rhodobacter sphaeroides as heavy metal removal tool. Annali di Chimica, 96, 195-203.

29. Vílchez, R., Gómez-Silván, C., Purswani, J., González-López, J., \& Rodelas, B. (2011). Characterization of bacterial communities exposed to $\mathrm{Cr}(\mathrm{III})$ and $\mathrm{Pb}$ (II) in submerged fixed-bed biofilms for groundwater treatment. Ecotoxicology, 20, 779-792.

30. Su, Y.-Q., Zhao, Y.-J., Zhang, W.-J., Chen, G.-C., Qin, H., Qiao, D.-R., Chen, Y.-E., \& Cao, Y. (2020). Removal of mercury(II), lead(II) and cadmium(II) from aqueous solutions using Rhodobacter sphaeroides SC01. Chemosphere, 243, 125166.

31. Mukkata, K., Kantachote, D., Wittayaweerasak, B., Techkarnjanaruk, S., Mallavarapu, M., \& Naidu, R. (2015). Distribution of mercury in shrimp ponds and volatilization of hg by isolated resistant purple nonsulfur bacteria. Water, Air, \& Soil Pollution, $2015,226$.

32. Fan, W., Jia, Y., Li, X., Jiang, W., \& Lu, L. (2012). Phytoavailability and geospeciation of cadmium in contaminated soil remediated by Rhodobacter sphaeroides. Chemosphere, 88, 751-756.

33. Li, X., Peng, W., Jia, Y., Lu, L., \& Fan, W. (2016). Bioremediation of lead contaminated soil with Rhodobacter sphaeroides. Chemosphere, 156, 228-235.

34. Asztalos, E., Italiano, F., Milano, F., Maroti, P., \& Trotta, M. (2010). Early detection of mercury contamination by fluorescence induction of photosynthetic bacteria. Photochemical \& Photobiological Sciences, 9, 1218-1223.

35. Kis, M., Sipka, G., Asztalos, E., Razga, Z., \& Maroti, P. (2015). Purple non-sulfur photosynthetic bacteria monitor environmental stresses. Journal of Photochemistry and Photobiology B: Biology, $151,110-117$.

36. Bai, H.-J., Zhang, Z.-M., \& Gong, J. (2006). Biological synthesis of semiconductor zinc sulfide nanoparticles by immobilized Rhodobacter sphaeroides. Biotechnology Letters, 28, 1135-1139.

37. Bansal, V., Li, B., Liu, N., Li, Y., Jing, W., Fan, J., Li, D., Zhang, L., Zhang, X., Zhang, Z., \& Wang, L. (2014). Reduction of selenite to red elemental selenium by Rhodopseudomonas palustris strain N. PLOS ONE, 9, e95955.

38. Italiano, F., Agostiano, A., Belviso, B. D., Caliandro, R., Carrozzini, B., Comparelli, R., Melillo, M. T., Mesto, E., Tempesta, G., \& Trotta, M. (2018). Interaction between the photosynthetic anoxygenic microorganism Rhodobacter sphaeroides and soluble gold compounds. From toxicity to gold nanoparticle synthesis. Colloids and Surfaces. B, Biointerfaces, 172, 362-371.

39. Choi, Y., \& Lee, S. Y. (2020). Biosynthesis of inorganic nanomaterials using microbial cells and bacteriophages. Nature Reviews Chemistry, 4, 638-656.

40. Singh, R., Shedbalkar, U. U., Wadhwani, S. A., \& Chopade, B. A. (2015). Bacteriagenic silver nanoparticles: Synthesis, mechanism, 
and applications. Applied Microbiology and Biotechnology, 99, 4579-4593.

41. Krishnamurthy, S., \& Yun, Y.-S. (2013). Recovery of microbially synthesized gold nanoparticles using sodium citrate and detergents. Chemical Engineering Journal, 214, 253-261.

42. Lim, K., Macazo, F. C., Scholes, C., Chen, H., Sumampong, K., \& Minteer, S. D. (2020). Elucidating the mechanism behind the bionanomanufacturing of gold nanoparticles using Bacillus subtilis. ACS Applied Bio Materials, 3, 3859-3867.

43. Simoska, O., Gaffney, E. M., Minteer, S. D., Franzetti, A., Cristiani, P., Grattieri, M., \& Santoro, C. (2021). Recent trends and advances in microbial electrochemical sensing technologies: an overview. Current Opinion in Electrochemistry, 30, 100762.

44. Lovley, D. R., \& Malvankar, N. S. (2015). Seeing is believing: Novel imaging techniques help clarify microbial nanowire structure and function. Environmental Microbiology, 17, 2209-2215.

45. Pankratova, G., \& Gorton, L. (2017). Electrochemical communication between living cells and conductive surfaces. Current Opinion in Electrochemistry, 5, 193-202.

46. Grattieri, M. (2020). Purple bacteria photo-bioelectrochemistry: Enthralling challenges and opportunities. Photochemical \& Photobiological Sciences, 19, 424-435.

47. Xing, D., Zuo, Y., Cheng, S., Regan, J. M., \& Logan, B. E. (2008). Electricity generation by Rhodopseudomonas palustris DX-1. Environmental Science and Technology, 42, 4145-4151.

48. Hasan, K., Patil, S. A., Gorecki, K., Leech, D., Hagerhall, C., \& Gorton, L. (2013). Electrochemical communication between heterotrophically grown Rhodobacter capsulatus with electrodes mediated by an osmium redox polymer. Bioelectrochemistry, 93, 30-36.

49. Hasan, K., Reddy, K. V. R., Eßmann, V., Górecki, K., Conghaile, P. Ó., Schuhmann, W., Leech, D., Hägerhäll, C., \& Gorton, L. (2015). Electrochemical communication between electrodes and Rhodobacter capsulatus grown in different metabolic modes. Electroanalysis, 27, 118-127.

50. Grattieri, M., Rhodes, Z., Hickey, D. P., Beaver, K., \& Minteer, S. D. (2019). Understanding biophotocurrent generation in photosynthetic purple bacteria. ACS Catalysis, 9, 867-873.
51. Grattieri, M., Patterson, S., Copeland, J., Klunder, K., \& Minteer, S. D. (2020). Purple bacteria \& 3-D redox hydrogels for bioinspired photo-bioelectrocatalysis. Chemsuschem, 13, 230-237.

52. Gaffney, E. M., Grattieri, M., Beaver, K., Pham, J., McCartney, C., \& Minteer, S. D. (2020). Unveiling salinity effects on photobioelectrocatalysis through combination of bioinformatics and electrochemistry. Electrochimica Acta, 337, 135731.

53. Grattieri, M., Beaver, K., Gaffney, E., \& Minteer, S. D. (2019). Tuning purple bacteria salt-tolerance for photobioelectrochemical systems in saline environments. Faraday Discussions, 215, 15-25.

54. Borghese, R., Malferrari, M., Brucale, M., Ortolani, L., Franchini, M., Rapino, S., Borsetti, F., \& Zannoni, D. (2020). Structural and electrochemical characterization of lawsone-dependent production of tellurium-metal nanoprecipitates by photosynthetic cells of Rhodobacter capsulatus. Bioelectrochemistry, 133, 107456.

55. Sawa, M., Fantuzzi, A., Bombelli, P., Howe, C. J., Hellgardt, K., \& Nixon, P. J. (2017). Electricity generation from digitally printed cyanobacteria. Nature Communications, 8, 1327.

56. Pankratov, D., Zhao, J., Nur, M. A., Shen, F., Leech, D., Chi, Q., Pankratova, G., \& Gorton, L. (2019). The influence of surface composition of carbon nanotubes on the photobioelectrochemical activity of thylakoid bioanodes mediated by osmium-complex modified redox polymer. Electrochimica Acta, 310, 20-25.

57. Weliwatte, N. S., Grattieri, M., Simoska, O., Rhodes, Z., \& Minteer, S. D. (2021). Unbranched hybrid conducting redox polymers for intact chloroplast-based photobioelectrocatalysis. Langmuir: The ACS Journal of Surfaces and Colloids, 37, 7821-7833.

58. Schuergers, N., Werlang, C., Ajo-Franklin, C. M., \& Boghossian, A. A. (2017). A synthetic biology approach to engineering living photovoltaics. Energy \& Environmental Science, 10, 1102-1115.

59. Grattieri, M., Beaver, K., Gaffney, E. M., Dong, F., \& Minteer, S. D. (2020). Advancing the fundamental understanding and practical applications of photo-bioelectrocatalysis. Chemical Coтmunications, 56, 8553-8568.

60. Gaffney, E. M., Grattieri, M., Rhodes, Z., \& Minteer, S. D. (2020). Exploration of computational approaches for understanding microbial electrochemical systems: opportunities and future directions. Journal of the Electrochemical Society, 167, 065502.

\section{Authors and Affiliations}

\section{Matteo Grattieri ${ }^{1,2} \mathbb{D} \cdot$ Rossella Labarile $^{1,2} \mathbb{D} \cdot$ Gabriella Buscemi $^{1,2}\left(\mathbb{D} \cdot\right.$ Massimo Trotta $^{2}$ D}

1 Dipartimento di Chimica, Università degli Studi di Bari "Aldo Moro", via E. Orabona 4, 70125 Bari, Italy
2 Consiglio Nazionale delle Ricerche, IPCF-CNR Istituto per i Processi Chimico Fisici, via E. Orabona 4, 70125 Bari, Italy 